\begin{tabular}{ll}
\hline & $\begin{array}{l}\text { Kastamonu Eğitim Dergisi } \\
\text { Kastamonu Education Journal }\end{array}$ \\
$\begin{array}{l}\text { Mayıs } 2019 \text { Cilt:27 Sayı:3 } \\
\text { kefdergi.kastamonu.edu.tr }\end{array}$ & Başuru Tarihi/Received: 24.01 .2018 \\
Kabul Tarihi/Accepted: 31.05 .2018 \\
Dol: $10.24106 /$ kefdergi.2595
\end{tabular}

\title{
Ortaokul Öğrencilerinde Yalnızlığın Yordayıcısı Olarak Olumlu-Olumsuz Mükemmelliyetçilik ${ }^{1}$
}

\section{Positive-Negative Perfectionism as Predictors of Loneliness among Secondary School Students}

\author{
Öz \\ Ali KARABABA ${ }^{2}$
}

Bu araştırmanın amacı ortaokul öğrencilerinde yalnızlık ile olumlu-olumsuz mükemmelliyetçilik arasındaki ilişkinin incelenmesidir. Araştırmadaki veri seti 2016-2017 eğitim-öğretim yılında, araştırmaya gönüllü olarak katılmayı kabul eden toplam 358 (169 kız-189 erkek) ortaokul öğrencisinden elde edilmiştir. Bu araştırma ilişkisel tarama modeli çerçevesinde gerçekleştirilmiştir. Araştrrmada veri toplama araçları olarak "Olumlu ve Olumsuz Mükemmelliyetçilik Ölçeği" ve "UCLA Yalnızık Ölçeği" kullanılmıştır. Analizler SPSS 16.0 paket programı yardımıyla test edilmiştir. Araştırma bulgularına göre yalnızlık olumlu mükemmelliyetçilik ile negatif; olumsuz mükemmelliyetçilik ile ise pozitif yönde anlamlı ilişki göstermektedir. Ayrıca, araştırma bulguları ortaokul öğrencilerinde olumlu mükemmelliyetçiliğin yalnızlı̆ın negatif yönde; olumsuz mükemmelliyetçiliğin ise pozitif yönde anlamlı bir yordayıcısı olduğunu göstermiştir.

\section{Anahtar Kelimeler: yalnızlık, olumlu mükemmelliyetçilik, olumsuz mükemmelliyetçilik}

\section{Abstract}

The aim of this study was to examine relationship between loneliness and positive-negative perfectionism among secondary school students. The data of the study was obtained from a total of 358 secondary school students (169 female-189 male), who were accepting to participate in the research voluntarily, during 2016-2017 academic year. This research was carried out by using relational survey model. In the study, scales were used as data collection tools as follows: "Positive and Negative Perfectionism Scale" and "UCLA Loneliness Scale". The analyses were tested with the help of SPSS 16.0 package program. It was seen that there was negatively relationship between positive perfectionism and loneliness; there was positively relationship between negative perfectionism and loneliness. The results of the study showed that positive perfectionism was a negatively predictor of loneliness; negative perfectionism was a positively predictor of loneliness among secondary school students.

Keywords: Ioneliness, positive perfectionism, negative perfectionism

1. Bu çalışma 18-21 Ekim 2017 tarihinde Alanya'da gerçekleştirilen II. International Academic Research Congress'de sözlü bildiri olarak sunulmuştur.

2. Uşak Üniversitesi, Rehberlik ve Psikolojik Danışmanlık Anabilim Dalı, Uşak, Türkiye; https://orcid.org/0000-0003-0458-3437

Atıf / Citation: Karababa, A. (2019). Ortaokul öğrencilerinde yalnızlığın yordayıcısı olarak olumlu-olumsuz mükemmelliyetçilik.Kastamonu Education Journal, 27(3), 1093-1101. doi:10.24106/kefdergi.2595 


\section{Extended Summary}

Purpose: The purpose of this study was to examine the relationship between loneliness and positive-negative perfectionism among secondary school students. Positive-negative perfectionism was investigated as a predictor of loneliness in the study.

Method: The data of the study was obtained from a total of 358 secondary school students (169 famele-189 male), who were accepting to participate in the research voluntarily, during 2016-2017 academic year. 79 of the participants were 5th grade (21.6\%), 92 were 6th grade $(25.1 \%), 96$ were 7 th grade $(25.7 \%)$ and 91 were 8 th grade $(27.5 \%)$ students. This research was carried out by using relational survey model. In the study, scales were used as data collection tools as follows: "Positive and Negative Perfectionism Scale" developed by Kırdök (2004) and "UCLA Loneliness Scale" developed by Russel, Peplau and Ferguson (1978) and adapted to Turkish by Demir (1989). The analyses were tested with the help of SPSS 16.0 package program with .01 and .05 levels of significance. The correlation and regression analyses were used in order to analyze the data.

Findings: In the research, it was seen that there was a negatively relationship between positive perfectionism and loneliness $(r=-.22, p<.05)$; there was a positively relationship between negative perfectionism and loneliness $(r=-.20, p<.05)$. The results of the study showed that positive perfectionism was a negatively predictor of loneliness $\left(R=.22, R^{2}=.05, F(1-356)=17.405, p<.01\right)$; negative perfectionism was a positively predictor of loneliness $(R=.20$, $\left.\mathrm{R}^{2}=.04, \mathrm{~F}_{1-356}\right)=15.494, \mathrm{p}<.01$ ) among secondary school students. In the findings, it was seen that positive perfectionism explained $5 \%$ of the total variance of loneliness' level; negative perfectionism explained $4 \%$ of the total variance of loneliness' level.

Results and Discussion: Considering the results of the research, it can be said that as level of positive perfectionism increases, level of loneliness decreases; as level of negative perfectionism increases, level of loneliness also increases among secondary school students. In one sense, the result of the study shows role of personality construction in the feeling of loneliness. Considering the literature, we see the researches that have parallels with the present study, role of personality on loneliness, concerning effect of personality on loneliness. Karataş-Karayel (2011) investigated relationship between perfectionism and loneliness among high school students and the study has shown that perfectionism plays a role in loneliness. Keldal and Atli (2016) examined relationship between personality and loneliness among university students and they have got result that open to experience, agreeableness, neuroticism, extroversion dimensions of personality are significant predictors of loneliness. Also, in the study of Teppers et al. (2013) on adolescents, we see the same result by reaching significant finding of relationship between loneliness and personality.

In the present study, it seen that there is a negatively significant relationship between positive perfectionism and loneliness. One of constructions of positive perfectionism is organisation. In the research of Karataş-Karayel (2011) among high school students, it can be said that result of negative relationship between loneliness and organisation has parallels with the finding the present study. Positive perfectionists have more realistic high standards (Enns et al., 2002). When it is thought that aims of positive perfectionists for social network are more accessible, it can be expected that these individuals will be more likely to obtain relationship satisfaction which they desire. In the present study, contrary to positive perfectionism, it seen that there is a positively significant relationship between positive perfectionism and loneliness. One of characteristics negative perfectionists is that they have unapproachable and nonlogical aims (Enns vd., 2002). Determining aims beyond such reality within the context of social network reduces the possibility of obtaining the social network which they want to be in. So, it can be said that possibility of negative perfectionists to experience loneliness increases.

As a result, the results of the study show that positive perfectionism is negatively predictor of loneliness; negative perfectionism is positively predictor of loneliness among secondary school students. It can be said that the present research has some limitations. Firstly, this research was carried out by using relational survey model. Also, the datas of the research were obtained from a secondary school in Pamukkale and Merkezefendi central districts of Denizli city. It is important that role of positive-negative perfectionism on loneliness is conducted with qualitative research method. Also, it is important that the problem of the research is conducted with different sample groups. The present research has shown personality's role in loneliness. Therefore, to enhance their awareness concerning their personality and general features, works in education institutions are important. We know that the approach of parents to their children in the information of a positive-negative perfectionist personality structure has an important role. Based on this, in the pre-school and primary school education institutions, guidance works such as seminars and group guidance on parental attitudes towards parents is important at this point. 


\section{Giriş}

Yalnızlık istenmeyen, hoş olmayan, acı veren özelliklere sahip (Perlman ve Peplau, 1984, s. 15-16) ve mutsuzluk, düşmanlık, korku, keder gibi olumsuz psikolojik yaşantıları da beraberinde getirebilen olumsuz duygulardan biridir (McWhirter, 1990). Yalnızlık, sosyal yalıtılmışlık ile eş anlamlı olmayan öznel değerlendirmenin sonucunda ortaya çıkan bir duygu durumudur. İsteğe bağıı olarak yaşanan yalnızlığın kişisel gelişimi destekleyici özelliği olsa da (Perıman ve Peplau, 1984); sosyal ilişkilerdeki yetersizliğin bir sonucu olarak hissedilen yalnızlık duygusu kişiyi hem psikolojik (Park ve Chang, 2004) hem de fiziksel olarak (Hawkley, Burleson, Berntson ve Cacioppo, 2003) olumsuz etkileyebilen bir yaşantıdır. Peplau ve Perıman (1982) yalnızlık duygusunu, bireyin sosyal ilişki ağında niceliksel veya niteliksel olarak önemli derecede bir yetersizlik meydana geldiğinde ortaya çıkan, hoş olmayan bir yaşantı olarak tanımlamıştır. Onlara göre, sahip olunan ile olmak istenilen sosyal ilişki ağı arasında bir uyuşmazlık varsa kişi yalnızlık duygusu hisseder. ỉhtiyaçlar temelinde kavramı ele alan Weiss'e $(1973$, s. 17) göre yalnızlık, ihtiyaç duyulan belli ilişki veya ilişki tarzlarının yoksunluğuna gösterilen bir tepkidir. De Jong-Gierveld (1998) yalnızlığı, bireyin sahip olduğu ile sahip olmayı arzu ettiği kişilerarası ilişkiler arasında fark hissettiğinde ve istediği ilişki ağını oluşturmada kendini kişisel olarak yetersiz algılamasının sonucunda ortaya çıkan bir durum olarak değerlendirmiştir.

Yalnızlık, bireyin sosyal ilişkilerinden aldığı doyum ve bunu algılama biçimi ile ilgilidir (Peplau ve Perlman, 1982). Birey başka kişilerle çok az düzeyde ilişki kuruyor olabilir, ancak ilişki düzeyinden memnunsa kendini yalnız hissetmeyecektir. Aksine, birey çok sayıda arkadaşı olduğu halde daha fazla sayıda ve yakınılıkta arkadaşa ihtiyaç duyup kendini yalnız hissedebilir (Burger, 2006; De Jong-Gierveld, Tilburg ve Dykstra, 2006: 486). Diğer bir ifadeyle yalnızlık, ilişkinin nicel özelliklerinden ziyade nitel durumu ile ilgili bir problem durumu olarak değerlendirilir. Literatür incelendiğinde, öznel bir değerlendirmenin sonucu olarak kavramsallaştrılan yalnızlık duygusunun yaşam doyumu (Kong ve You, 2013), benlik saygısı (Vanhalst, Luyckx, Scholte, Engels ve Goossens, 2013), okula bağlanma (Duy ve Yildiz, 2014), umut (Yarcheski, Mahon ve Yarcheski, 2011) gibi olumlu psikolojik yaşantllar ile negatif yönlü; depresyon (Park ve Chang, 2004; Wang, Yuen ve Slaney, 2009), fiziksel sağlik problemleri (Hawkley vd., 2003), kaygı semptomları (Chang, Hirsch, Sanna, Jeglic ve Fabian, 2011), intihar olasılığı (Page vd., 2006) gibi olumsuz psikolojik yaşantılarla ise pozitif yönlü ilişki içinde olduğu görülmektedir.

Araştırma bulguları yalnızık duygusunda birçok faktörün rol oynayabildiğini göstermiştir. Bunlar arasında bilişsel faktörler (Peplau ve Perlman, 1982; Peplau, 1988); işten çıkarılma, yakın birinin kaybı gibi beklenmedik olaylar ve evlilik durumu, ekonomik gelir vb. demografik değişkenler (Perlman ve Peplau, 1981; Peplau, 1985; Perlman ve Peplau, 1998); çocukluk çağı yaşantıları ve kültürel faktörler gösterilebilir (Perlman ve Peplau, 1984). Bunların dışında yalnızlık düzeyinde rol oynayan önemli değişkenlerden biri de kişiliktir. Gerçekleştirilen çalışmalar, kişilik yapılarının yalnızlık düzeyinde güçlü derecede rol oynayan bir faktör olduğunu göstermiştir (Cheng ve Furnham, 2002; Perlman ve Peplau, 1984; Vanhalst vd., 2012). Karababa ve Dilmaç (2016) TA kuramı ışı̆ı̀nda lise öğrenimine devam eden ergen grubunda gerçekleştirdikleri çalışmada; kişilik yapısının bir yansıması olarak bireylerin iletişim sürecindeki tutum, yaklaşım ve davranışların onların yalnızlık düzeyinde belirleyici bir role sahip olduğu bulgusu elde edilmiştir. Keldal ve Atli (2016) üniversite öğrencilerinde yalnızlık ile kişilik arasındaki ilişkiyi araştıdıkları çalışmada, deneyime açıklık, uyumluluk, nevrotiklik ve dışadönüklük kişilik özelliklerinin yalnızlığın anlamlı bir yordayıcısı olduğuna ilişkin bir sonuç elde etmiştir. Ayrıca, Teppers ve arkadaşlarının (2013) ergenler üzerinde gerçekleştirdikleri çalışmada dışadönüklük ve uyumluluk kişilik özelliklerinin yalnızlık duygusunun negatif yönlü anlamlı yordayııları olduğu bulgusuna ulaşarak benzer bir sonuç elde edilmiştir.

Yalnızlık düzeyinde rol oynayan kişilik yapılarından biri de mükemmelliyetçiliktir (Karataş-Karayel, 2011; Kaya ve Birol, 2018). Alanyazın incelendiğinde başlarda mükemmelliyetçi kişilik özelliğinin tek boyutlu ve olumsuz bir yapı olarak ele alındığı görülürken (Burns, 1980); 1990'lı yıllardan itibaren kavramın olumlu yanlarııın da olabileceği tartş̧ımış ve çok boyutlu olarak kavramsallaştırılmıştır (Frost, Marten, Lahart ve Rosenblate, 1990; Hewitt ve Flett, 1991; Slaney, Rice, Mobley, Trippi ve Ashby, 2001). Slaney ve arkadaşları (2001) olumlu mükemmelliyetçiliği yüksek standartlar ve düzen ile temellendirirken, olumsuz mükemmelliyetçiliği ise standart ile performans arasındaki çelişkinin ortaya çıkardığı stres durumu ile kavramsallaştırmıştır. Yeteneklerine ve kendilerine ilişkin farkındalıkları yüksek olan olumlu mükemmelliyetçi bireyler, daha gerçekçi ve mantık dışı olmayan hedefler belirlemektedir. Bu nedenle bu bireylerin amaçlarına ulaşabilme ve performanslarını karşılayabilme düzeyi daha yüksektir. Olumlu mükemmelliyetçi kişilik yapısına sahip bireyler şartların izin verdiği oranda mükemmellik beklerler. Herhangi bir başarısızlık durumunda ise bunu kabul etme ve çabalarını yenileyebilme düzeyleri daha yüksektir. Hata yapma korkusu üzerine odaklanan olumsuz mükemmelliyetçi bireyler ise ulaşılmaz nitelikte ve mantıkdışı hedeflere sahiptirler ve ya hep ya hiç ilkesi üzerine kurulu başarı standartları mevcuttur. Bu bireylerin hatalara karşı tahammül eşikleri düşüktür ve herhangi bir başarısızlık karşısında kolayca 
umutsuzluk, yetersizlik ve aşağılık gibi duygular geliştirebilmektedirler (Enns, Cox ve Clara, 2002; Slaney vd., 2001).

Yalnızlık duygusunun en yoğun hissedildiği gelişim dönemi ergenliktir (Brennan, 1982; Rubenstein ve Shaver, 1982). Ergen yalnızlığı yukarıda da ifade edildiği üzere sadece ergenlikte fiziksel ve psikolojik olumsuz sonuçlar ile ilişkili değil aynı zamanda yetişkin yaşamı açısından uzun ve sağlıklı bir sürece ilişkin de risk oluşturmaktadır (Hawkley ve Cacioppo, 2010). Bu araştırmada yalnızlık duygusunun ele alındığı çalışma grubunu ortaokul öğrencileri oluşturmaktadır. Ortaokul süreci büyük oranda ön ergenlik dönemine denk gelen bir gelişim sürecini kapsar (Santrock, 2012). Bir anlamda, ortaokula geçişle birlikte bireyler bedensel, bilişsel ve sosyal-duygusal olmak üzere bütünsel farklılaşmaların yanı sıra, bir öğretmenden çok öğretmenliğe geçiş, başarının ve performansın daha ön planda olduğu bir sisteme uyum sağlama gibi akademik değişimlerle de karşı karşıya kalmaktadır (Santrock, 2014). Ayrıca, ön ergenlik duygusal iniş çıkışların daha sık olarak görüldüğü bir dönemdir (Santrock, 2012, s. 150). Bundan dolayı ortaokul yılları zorlu bir gelişim ve akademik dönem haline gelebilmektedir. Ergen farklı ve zorlu gelişimsel alanlarda kendine yeni hedefler belirleyebilmekte veya dışarıdan kendisi için yeni beklentiler sunulabilmektedir. Ergenlik dönemi sosyal iletişim ağının yeniden tanımlanması ile karakterize edilen bir dönemdir ve bu sürecin başlangıcı ön ergenlik dönemine uzanır. Bu dönemde ergen bireyler ebeveynlerine duygusal bağımlılıklarından uzaklaşarak daha özerk yetişkin davranışlarına yönelim gösterirler. Ayrıca, akranları ile ilişkilerinde daha büyük ve anlamlı bir yakınlık elde etme çabası içindedirler (Teppers vd., 2013). Antony ve Swinson (2000) sosyal ilişkilerde yüksek beklentilere sahip ergenlerin sosyal kaygı ile ilgili problemler yaşadıklarını ve yalnızlık yaşayabileceklerini ifade etmiştir. Ayrıca, bu yoğun değişim döneminde öğrenciler akademik ve diğer yaşantısal alanlarda başarısızlıklarla karşı karşıya gelebilmektedir. Araştırmalar yalnızlık duygusu yaşayan öğrencilerin hedeflerine ulaşamadıklarında başkaları tarafindan olumsuz değerlendirilmekten çekinen kişiler olduklarını göstermiştir (Storch ve Masia-Warner, 2004). Bu noktada bireylerin hedeflerinin gerçeklik düzeyi ve herhangi bir başarısızık anında bu durumun başkaları tarafindan nasıl algılandığının önemli bir durum olduğu görülmektedir. Yalnızlığın bireyin sahip olduğu ile arzu ettiği ilişki ağı arasındaki fark olarak tanımlandığı dikkate alındığında (Peplau ve Perıman, 1982); yalnızlık duygusu bireyin içinde bulunduğu döneme uyumu olarak düşünülebilir (Asendorpf ve Van-Aken, 2003). Bireyin adaptasyonu kişilikle ilişkilidir (Asendorpf ve Van-Aken, 2003). Bundan dolayı bu araştırmada yalnızlık duygusunda bir kişilik özelliği olarak olumlu-olumsuz mükemmelliyetçiliğin yordayııı rolü incelenmiştir. Bu bilgiler ışığında, ortaokul öğrencilerinde psikolojik ve fiziksel sağlık üzerinde negatif yönde yordayıcı role sahip yalnızlık duygusunda rol oynayabilecek faktörlerin belirlenmesi önemlidir. Literatür incelendiğinde ortaokul öğrencilerinde olumlu-olumsuz mükemmelliyetçilik ile yalnızlık arasındaki ilişkiyi inceleyen herhangi bir çalışmaya rastlanmamıştr. Bu açıdan, mevcut çalışmanın hem alan yazındaki boşluğu dolduracağı hem de gelecek çalışmalara ve önleyicilik özelliği taşıyan programlara ışık tutacağı beklenmektedir.

\section{Araştırmanın Amacı}

Yukarıdaki açıklamalar doğrultusunda, bu araştırma ile ortaokul öğrencilerinde olumlu ve olumsuz mükemmelliyetçiliğin yalnızlığı yordamadaki rolünün incelenmesi amaçlanmaktadır.

\section{Araştırmanın Problemi}

Araştırmanın amacına bağlı olarak çalışmada şu alt problemlere yanıt aranmıştır:

- Ortaokul öğrencilerinde olumlu mükemmelliyetçilik yalnızlığı anlamlı şekilde yordamakta mıdır?

- Ortaokul öğrencilerinde olumsuz mükemmelliyetçilik yalnızlı̆ı anlamlı şekilde yordamakta mıdır?

\section{Yöntem}

\section{Çalışma Grubu}

Araştırmanın amacı kapsamında, çalışma ilişkisel tarama modeline uygun olarak gerçekleştirilmiştir. Araştırmanın çalışma grubu 2016-2017 eğitim-öğretim yılında, ulaşılabilen ve araştırmaya gönüllü olarak katılmayı kabul eden toplam 358 ortaokul öğrencisinden (169 kız-189 erkek) oluşmaktadır. Katılımcıların 79'u 5. sınıf (\%22.1), 92'si 6. sınıf (\%25.7), 96'sı 7. sınıf (\%26.8) ve 91'si ise 8. sınıf (\%25.4) öğrencisidir.

\section{Veri Toplama Araçları}

Araştırmada katılımcı grubun yalnızlık düzeyini belirlemek için UCLA Yalnızlık Ölçeği kullanılmıştır. UCLA Yalnızlık Ölçeği Russel, Peplau ve Ferguson (1978) tarafindan geliştirilmiş, Russel, Peplau ve Cutrona (1980) tarafindan iki yıl sonra revize edilmiş ve Demir (1989) tarafindan Türkçeye uyarlanmıştr. 20 maddeden oluşan ölçek 4'lü Likert özelliğindedir. Ölçekten elde edilecek en yüksek puan 80 iken, en düşük puan 20'dir. Ölçekten elde edilen puan yükseldikçe yalnızlık düzeyi de yükselir. Revize çalışmasında ölçeğin iç tutarlık katsayısı .94 olarak hesaplanırken; iki ay ara ile gerçekleştirilen 
test-tekrar test güvenirlik katsayısı ise .73 'tür (Russell vd., 1980). Türkçeye uyarlama çalışmasında, ölçeğin iç tutarlılık katsayısı .96; beş hafta ara ile gerçekleştirilen test-tekrar test güvenirlik katsayısı ise .94 olarak bulunmuştur. Bu araştirmada ölçeğin iç tutarlılık katsayısı .90 olarak hesaplanmıştır.

Katlımcıların olumlu ve olumsuz mükemmelliyetçilik düzeylerinin belirlenmesinde Olumlu ve Olumsuz Mükemmelliyetçilik Ölçeği kullanılmıştır. Ölçek Kırdök (2004) tarafindan geliştirilmiştir. Olumlu mükemmelliyetçilik (10 madde) ve olumsuz mükemmelliyetçilik ( 7 madde) olmak üzere iki alt boyuta sahip ölçek toplamda 17 maddeden oluşmaktadır. Her iki boyut içinde geçerli olmak üzere, alınan puanın yükselmesi olumlu-olumsuz mükemmelliyetçilik düzeyinin de yükseleceğini bildirmektedir. Ölçeğin güvenirlik çalışmasında, Cronbach alfa katsayısı olumlu mükemmeliyetçilik boyutu için .81 ve olumsuz mükemmeliyetçilik boyutu için ise .78 olarak hesaplanmıştı. Olumlu ve Olumsuz Mükemmelliyetçilik Ölçeği'nin test tekrar test çalışmasında güvenirlik katsayılarına bakıldığında, olumlu mükemmelliyetçilik boyutu için .75 ve olumsuz mükemmelliyetçilik boyutu için ise .78 olduğu görülmektedir. Bu çalışma için olumlu mükemmelliyetçilik alt boyutunun iç tutarlılık katsayısı .86; olumsuz mükemmelliyetçilik alt boyutu için ise .76 olarak hesaplanmıştır.

\section{İşlem}

Yalnızık duygusu ile olumlu-olumsuz mükemmelliyetçilik kişilik yapısı arasındaki ilişkiyi incelemek üzere çalışma kapsamında ulaşılan veri seti, 2016-2017 eğitim-öğretim yılında, ulaşılabilen ve araştırmaya gönüllü olarak katılmayı kabul ortaokul öğrencilerinden elde edilmiştir. Çalışma grubundan verilerin elde edilme işleminden önce katılımcılara çalışmanın amacı, ölçme araçlarının cevaplanması konularında açıklamalar yapılmıştır. Uygulama çalışması sınıf ortamında ve araştırmacı tarafindan gerçekleştirilmiştir. Ölçekler analize dahil edilmeden önce kontrol edilmiş ve eksik doldurulmuş formlar ayırt edilmiştir. Verilerin analiz sürecinde SPSS 16. programı kullanılmıştır. Çalışmada yalnızık bağımlı, olumlu-olumsuz mükemmelliyetçilik ise bağımsız değişken olarak ele alınmıştı. Değişkenler arasındaki ilişki düzeylerinin saptanmasında Pearson Korelasyon Çarpımı Korelasyon Katsayısı ve bağımsız değişkenin bağımlı değişkeni yordayıp yordamadığını belirlemek amacıyla ise basit-doğrusal regresyon analizi kullanılmıştır.

\section{Bulgular ve Yorumlar}

Çalışmada araştırılacak değişkenler arası korelasyonlar ve olumlu-olumsuz mükemmelliyetçilik kişilik yapısı bağımsız değişkeninin yalnızlık bağımlı değişkenini yordayıp yordamadığına ilişkin analiz sonuçları bu bölümde verilmiştir.

Tablo 1. Olumlu-Olumsuz Mükemmelliyetçilik ve Yalnızlık Değişkenleri Arasındaki ilişkileri Gösteren Korelasyon Değerleri

\begin{tabular}{lccccccc}
\hline Değişkenler & 1 & 2 & 3 & Ort. & S.s. & Bas. & Çar. \\
\hline Yalnızlık (1) & - & & & 64.86 & 11.63 & .32 & -1.02 \\
Olumlu Mükemmelliyetçilik (2) & $-.22^{*}$ & - & & 32.19 & 5.52 & .53 & -.79 \\
Olumsuz Mükemmelliyetçilik (3) & $.20^{*}$ & .06 & - & 18.64 & 4.72 & .78 & -.19 \\
\hline${ }^{*}<<.01$
\end{tabular}

Ortaokul öğrencilerinde yalnızlık düzeyinde olumlu-olumsuz mükemmelliyetçilik kişilik özelliğinin yordayıcı rolünün belirlenmesine yönelik analiz işleminden önce değişkenlere ilişkin tanımlayıcı istatistikler araştııımıştı (Tablo 1). Değişkenlerin çarpıklık ve basıklık değerleri incelendiğinde, değerlerin 1.02 ile .86 arasında olduğu görülmektedir. Bu bulgular dikkate alındığında değişkenlere ilişkin normallik koşulunun sağlandığı ifade edilebilir.

Tablo 1'deki analiz sonuçları göz önünde bulundurulduğunda, yalnızlık düzeyinin olumlu mükemmelliyetçilik ( $r=$ $-.22, p<.01)$ ile negatif; olumsuz mükemmelliyetçilik düzeyi $(r=.20, p<.05)$ ile ise pozitif yönde anlamlı ilişki içinde olduğu görülmüştür.

Tablo 2. Olumlu-Olumsuz Mükemmelliyetçilik Kişilik Özelliğinin Yalnızlık Düzeyini Yordamasına Iliş̧in Basit Doğrusal Regresyon Analizi Sonucu

\begin{tabular}{llccccccccc}
\hline Yordanan Değişken & Yordayıcı Değişken & Ort. & B & St. H. & Beta & t & F & $p$ & $R$ & $R^{2}$ \\
\hline \multirow{2}{*}{ Yalnızlık } & Olumlu Mükem. & 32.19 & -.46 & .109 & -.216 & -4.172 & 17.405 & .00 & .22 & .05 \\
& Olumsuz Mükem. & 18.64 & .50 & .128 & .204 & 3.936 & 15.494 & .00 & .20 & .04 \\
\hline
\end{tabular}

${ }^{*} \mathrm{p}<.01$

Tablo 2'de verilen regresyon analiz sonucuna göre, ortaokul öğrencilerinde olumlu mükemmelliyetçilik düşük düzeyde negatif yönde $\left(R=.22, R^{2}=.05, F\left(\begin{array}{l}1-356 \\ )\end{array}\right)=17.405, p<.01\right)$; olumsuz mükemmelliyetçilik ise düşük düzeyde pozitif yönde 
$\left.\left(\mathrm{R}=.20, \mathrm{R}^{2}=.04, \mathrm{~F}_{1-356}\right)=15.494, \mathrm{p}<.01\right)$ yalnızlık düzeyini anlamlı düzeyde yordamaktadır. Olumlu mükemmelliyetçilik yalnızlık düzeyine ilişkin toplam varyansın yaklaşık \%5'ini açıklarken; olumsuz mükemmelliyetçilik ise toplam varyansın yaklaşık \%4'ünü açıklamaktadır.

\section{Tartışma}

Bu araştırmayla ortaokul öğrencilerinde olumlu ve olumsuz mükemmelliyetçiliğin yalnızlığı yordamadaki rolünün incelenmesi amaçlanmıştır. Araştırma bulgusu ortaokul öğrencilerinde yalnızlık duygusunun olumlu mükemmelliyetçilik ile negatif yönde; olumsuz mükemmelliyetçilik ile ise pozitif yönde anlamlı bir ilişki içinde olduğunu göstermiştir. Ayrıca, mevcut araştırmada olumlu ve olumsuz mükemmelliyetçiliğin yalnızlık düzeyinde yordayıcı bir role sahip olduğuna yönelik bir bulgu elde edilmiştir. Araştırma bulgularına göre ortaokul öğrencilerinde olumlu mükemmelliyetçilik düzeyi yükseldikçe ve olumsuz mükemmelliyetçilik düzeyi ise azaldıkça yalnızlık düzeyi azalmaktadır. Araştırma sonucu bir anlamda yalnızlık duygusunda kişilik yapısının rolünü ortaya koymuştur. Literatür incelendiğinde, kişilik yapısı özelliğinin yalnızlık duygusu üzerindeki belirleyiciliğine yönelik mevcut araştırma bulgusu ile paralellik gösteren çalışmalara rastlanıımaktadır. Karataş-Karayel (2011) lise öğrencilerinde mükemmelliyetçilik ile yalnızlık arasındaki ilişkiyi araştırdığı çalışmada mükemmelliyetçi kişilik yapısının yalnızlık duygusundaki rolünün varlığına ilişkin bir sonuca ulaşmıştır. Keldal ve Atli (2016) üniversite öğrencilerinde yalnızlık ile kişilik arasındaki ilişkiyi araştrdıkları çalışmada, deneyime açıklık, uyumluluk, nevrotiklik ve dışadönüklük kişilik özelliklerinin yalnızlığın anlamlı bir yordayıcısı olduğuna ilişkin bir sonuç elde etmiştir. Ayrıca, Teppers ve arkadaşlarının (2013) ergenler üzerinde gerçekleştirdikleri çalışmada yalnızlık ile kişilik özellikleri arasında anlamlı ilişki bulgusuna ulaşılarak benzer bir sonuç elde edilmiştir. Teppers vd.'nin (2013) çalışmasında dışadönüklük ve uyumluluk kişilik özelliklerinin yalnızlığın negatif yönlü anlamlı yordayıcıları olduğu görülmüştür. Jackson, Soderlind ve Weiss (2000) iyimser kişilik özelliğine sahip kişilerin daha düşük düzeyde yalnızlık duygusuna sahip olduklarını ifade etmiştir. Bireylerin kişilerarası ilişkilerde nasıl bir tutum içinde olacağını, kişilere, olaylara ne tür bir tepki vereceğini belirleyen ayrıca içinde bulunulan yaşantıyı anlamlandırmada rol oynayan önemli bir faktör kişiliktir (Burger, 2006). Yalnızlık duygusunun bireyin sosyal ilişkilerinden aldığı doyum ve bunu algılama biçimi ile ilişkili olduğu göz önüne alındığında (Peplau ve Perıman, 1982); yalnızlık duygusunda kişiliğin rol oynaması beklenilen bir araştırma bulgusu olarak değerlendirilebilir. Ayrıca, yalnızlık duygusu bireyin içinde bulunduğu döneme uyumu olarak düşünülebilir (Asendorpf ve Van-Aken, 2003). Bireyin adaptasyonu onun kişiliği ile doğrudan ilişkilidir (Asendorpf ve Van-Aken, 2003). Bu çalışmada, ortaokul öğrencilerinde yalnızlık düzeyinde olumlu-olumsuz mükemmelliyetçilik kişilik yapısının rolü görülmektedir. Ortaokul süreci büyük oranda ön ergenlik dönemine denk gelen bir gelişim sürecini kapsar (Santrock, 2012). Bir anlamda, ortaokula geçişle birlikte bireyler bedensel, bilişsel ve sosyal-duygusal olmak üzere bütünsel farklılaşmaların yanı sıra, bir öğretmenden çok öğretmenliğe geçiş, başarııın ve performansın daha ön planda olduğu bir sisteme uyum sağlama gibi akademik değişimlerle de karşı karşıya kalmaktadır (Santrock, 2014). Ayrıca, ergenlik dönemi sosyal iletişim ağının yeniden tanımlanması ile karakterize edilen bir dönemdir ve bu sürecin başlangıcı ön ergenliğe dayanmaktadır. Bu dönemde ergen bireyler ebeveynlerine duygusal bağımlılıklarından uzaklaşarak daha özerk yetişkin davranışlarına yönelim gösterirler. Ayrıca, akranları ile ilişkilerinde daha büyük ve anlamlı bir yakınlık elde etme çabası içindedirler (Teppers vd., 2013). İstenilen sosyal ilişki ağına sahip olma açısından bireylerin beklenti düzeylerinin ne kadar mantıklı olup olmadığı ve gerçek düzeylerini nasıl değerlendirdikleri önemlidir. Antony ve Swinson (2000) sosyal ilişkilerde yüksek beklentilere sahip ergenlerin sosyal kaygı ile ilgili problemler yaşadıklarını ve yalnızlık yaşayabileceklerini ifade etmiştir.

Mevcut araştırma bulgusunda yalnızlık ile olumlu mükemmelliyetçilik arasında negatif yönde anlamlı bir ilişki görülmüştür. Literatürü incelediğimizde bu araştırma bulgusunu destekleyen çalışmaları görmekteyiz. Olumlu mükemmelliyetçiliği oluşturan yapılardan biri düzen alt boyutudur (Slaney vd., 2001). Karataş-Karayel'in (2011) lise öğrencileri ile gerçekleştirdiği çalışmada, yalnızık ile düzen arasındaki negatif yönlü ilişki bulgusunun mevcut araştırma bulgusu ile paralellik gösterdiği söylenebilir. Literatür dikkate alındığında olumlu mükemmelliyetçiliğin depresyona yatkınlık (Enns vd., 2002; Gnilka, Ashby ve Noble, 2011), mutsuzluk (Gnilka vd., 2011), öfke, fiziksel-sözel saldırganlık (Erol-Öngen, 2009) gibi olumsuz psikolojik yapılarla negatif ilişkisi olduğunu gösteren araştırma sonuçlarının mevcut araştırma bulgusunu dolaylı olarak desteklediği ifade edilebilir. Kavramsal literatürün mevcut araştırma bulgusunu desteklediği görülmektedir. Olumlu mükemmelliyetçi kişilik özelliğine sahip kişiler daha gerçekçi yüksek standartlara sahiptirler (Enns vd., 2002; Slaney vd., 2001). Bu açıdan bu bireylerin sosyal ilişki ağına yönelik hedeflerinin daha ulaşılabilir olduğu düşünüldüğünde istedikleri ilişki doyumunu elde etmelerinin daha olası olacağı beklenebilir. Ayrıca, olumlu mükemmelliyetçi bireyler herhangi bir başarısızlık durumunda umutsuzluğa kapılıp geriye çekilmek yerine olası çözüm yollarına yönelik fikirler üretmeye çabalayan kişilerdir (Enns vd., 2002; Slaney vd., 2001). Bundan dolayı, olumlu mükemmelliyetçi kişilik özelliğine sahip bireylerin istedikleri ilişki doyumunu yakalayamadıklarında kendi dünyalarına çekilmek yerine 
soruna ve çözüm yollarına odaklanmaları yüksek bir olasılıktır. Bu durumun kişilerin yalnızlığa neden olan faktörlerin ortadan kaldırılmasına yönelik çözüm yolu bulma olasılığını arttıracağı öngörülebilir.

Olumlu mükemmelliyetçiliğin aksine çalışmada yalnızlık ile olumsuz mükemmelliyetçilik arasında pozitif yönde anlamlı bir ilişki olduğu sonucuna ulaşılmıştır. Alanyazın incelendiğinde olumsuz mükemmelliyetçiliğin depresyona yatkınlık (Enns vd., 2002; Gnilka vd., 2011), mutsuzluk (Gnilka vd., 2011), sürekli kaygı (Comerchero ve Fortugno, 2013), öfke, fiziksel-sözel saldırganlık (Erol-Öngen, 2009) vb. olumsuz psikolojik yaşantılar ile pozitif yönde ilişki içinde olduğunu gösteren araştırma bulgularının mevcut araştırma sonucunu desteklediği görülmektedir. Olumsuz mükemmelliyetçi bireylerin temel özelliklerinden biri ulaşılması güç ve gerçek dışı hedefler belirlemeleridir (Enns vd., 2002). Kişilerin sosyal ilişki ağı kapsamında bu tür gerçekliğin ötesinde hedefler belirlemeleri onların içinde bulunmak istedikleri sosyal iletişim ağını elde etme olasılığını düşürmesi beklenebilir. Bundan dolayı olumsuz mükemmelliyetçi bireylerin yalnızlık duygusunu yaşama olasılığının arttğı ifade edilebilir. Ayrıca, olumsuz mükemmelliyetçi bireyler herhangi bir başarısızlık durumunda kaygı, depresyon gibi olumsuz duyguları yaşayabilmektedirler (Enns vd., 2002). Kaygı, depresyon gibi duygularla yalnızlık arasındaki pozitif yönlü yüksek ilişkinin varlığını gösteren araştırmaların (Chang vd., 2011; Park ve Chang, 2004) mevcut araştrrma bulgusu ile dolaylı olarak paralellik gösterdiği söylenebilir. Olumsuz mükemmelliyetçi kişilik özelliğinin temel özellikleri (Enns vd., 2002; Slaney vd., 2001); ayrıca Erol-Öngen'in (2009) ergenlerle gerçekleştirdiği çalışmada olumsuz mükemmelliyetçilik ile öfke, düşmanlık, fiziksel-sözel saldırganlık arasındaki pozitif yönlü ilişki bulguları dikkate alındığında olumsuz mükemmelliyetçi bireylerin kişiler arasındaki iletişimi zorlaşttran ve yıpratan bir takım özelliklere sahip oldukları görülmektedir. Buna istinaden, olumsuz mükemmelliyetçi kişilik özelliğine sahip bireylerin çevresindeki kişileri bu özellikleri sebebiyle kendilerinden uzaklaştrabileceği öngörülebilir. Sonuç olarak, mevcut araştrmada ortaokul öğrencilerinde yalnızlığı yordamada olumlu mükemmelliyetçiliğin negatif yönde, olumsuz mükemmelliyetçiliğin ise pozitif yönde anlamlı yordayıcılar olduğu belirlenmiştir. Bu sonuçla birlikte mevcut araştırmanın bazı sınırlıııklara sahip olduğu söylenebilir. Sonuçların bu sınırlııklar ışığında yorumlanması önemlidir. Öncelikle, araştırmada çalışmanın amacı doğrultusunda bulgulara ilişkisel model yolu takip edilerek ulaşılmıştır. Bundan dolayı, değişkenler arasında bir neden-sonuç ilişkisi kurulamaz. Bu ilişkiden söz edilmesi noktasında gelecek çalışmaların mevcut değişkenleri boylamsal ve deneysel çalışmalar ile test etmesi önemlidir. Bununla birlikte çalışmanın veri seti 2016/2017 eğitim-öğretim yılında Denizli/Pamukkale merkez ilçesindeki bir ortaokulda öğrenimine devam eden ve çalışmaya gönüllü olarak katımayı kabul eden 358 katılımcı ile sınırıdır. Bulguların genellenebilirliği açısından değişkenler arasındaki ilişkinin farklı kültür ve örneklem gruplarında incelenmesi önemli görülmektedir. Ayrıca, ortaokul öğrencilerinde olumlu-olumsuz mükemmelliyetçilik kişilik yapısının yalnızlık düzeyindeki rolünün daha somut ve derin çerçevede ele alınma noktasında nitel araştırma yöntemi ile araştırılmasının önemli olacağı düşünülmektedir. Görülmüştür ki ortaokul öğrencilerinin yalnızık duygusunda kişilik yapısı rol oynayabilmektedir. İçinde bulunulan olumsuz yaşantının üstesinden gelmenin en önemli faktörlerinden biri farkındalığa sahip olmaktır. Bundan dolayı eğitim kurumlarında öğrencilerin kişiliklerine ve genel özelliklerine ilişkin farkındalıklarının arttırımasına yönelik çalışmaların gerçekleştirilmesi önemlidir. Olumlu-olumsuz mükemmelliyetçi kişilik yapısının oluşumunda ebeveynlerin ve öğretmenlerin çocuklar üzerindeki yaklaşımı önemli bir işleve sahiptir. Ayrıca, sahip olduğumuz eğitim sistemi çocuklar arasında bir rekabet durumunu yaratmakta ve ebeveynlerin çocuklarından başarı yönelimli olarak beklentileri artmaktadır. Başarı yönelimli ebeveynler herhangi bir başarısızlık durumunda çocuklarına yönelik yaklaşımları olumsuz olmaktadır. Bu durum bireylerde olumsuz mükemmelliyetçilik kişilik özelliğinin gelişmesine neden olabilmektedir. Ebeveynlerin bu konuda bilinçlendirilmesi önemlidir. Buna istinaden, özellikle okul öncesi ve ilkokul eğitim kurumlarında ebeveynlere yönelik gerçekleştirilecek anne-baba tutumları konulu seminer, grup rehberliği ve eğitim programları çalışmaları önleyici bir rol üstlenecektir. Birçok olumsuz yaşant ile pozitif ilişki içinde olan yalnızlık duygusu özellikle ergenlik döneminde daha yıkıcı bir özellik gösterebilmektedir. Daha önce ifade edildiği gibi yalnızlık duygusunda birçok faktör rol oynayabilmektedir. Yalnızlığın sosyal ve ilişki temelli bir duygu durum problemi olduğu göz önüne alındığında; önleyici rehberlik çalışmaları ışı̆ında ön ergenlik döneminde bulunan bireylere yönelik gerçekleştirilecek iletişim ve duygu düzenleme becerileri konularında gerçekleştirilecek psiko-eğitim çalışmaları önemlidir.

\section{Kaynakça}

Antony, M. M. ve Swinson, R. P. (2000). When perfect isn't good enough: Strategies for coping with perfectionism. Oakland, CA: New Harbinger Publications.

Asendorpf, J. B. ve Van-Aken, M. A. G. (2003). Personality-relationship transaction in adolescence: Core versus surface personality charactersitics. Journal of Personality, 71, 629-666.

Brennan, T. (1982). Loneliness at Adolescences. In L. Peplau \& D. Perlman (Eds.). Loneliness: A sourcebook of current theory, research and therapy, (pp. 269-290). New York. John Wiley. 
Burger, J. M. (2006). Kişilik. (çev. İ. D. E. Sarıoğlu). İstanbul: Kaknüs Yayınları.

Burns, D. D. (1980). The perfectionist script for self-defeat. Psychology Today, 41, 34-51.

Chang, E. C., Hirsch, J. K., Sanna, L. J., Jeglic, E. L. ve Fabian, C. G. (2011). A preliminary study of perfectionism and loneliness as predictors of depressive and anxious symptoms in Latinas: A top-down test of a model. Journal of Counseling Psychology, 58(3), 441.

Cheng, H. ve Furnham, A. (2002). Personality, peer relations, and self-confidence as predictors of happiness and loneliness. Journal of Adolescence, 25, 327-339.

Comerchero, V. ve Fortugno, D. (2013). Adaptive perfectionism, maladaptive perfectionism and statistics anxiety in graduate psychology students. Psycology Learning and Teaching, 12(1), 4-11.

De Jong Gierveld, J. (1998). A review of loneliness: Concept and definitions, determinants and consequences. Reviews in Clinical Gerontology, 8, 73-80.

De Jong-Gierveld, J., Tilburg, T. V. ve Dykstra, P. A. (2006). Loneliness and social isolation. In Vangelisti, A. \& Perlman, D. (Eds.). Cambridge handbook of personal relationships (pp. 485-500). Cambridge: Cambridge University Press.

Demir, A. (1989). U.C.L.A. Yalnızlık Ölçeğinin geçerlik ve güvenilirliği. Psikoloji Dergisi, 7(23), 14-18.

Duy, B. ve Yildiz, M. A. (2014). School attachment and loneliness in early adolescents with different bully status. Education and Science, 39(174), 173-188.

Enns, W. M., Cox, B. J. ve Clara, I. (2002). Adaptive and maladaptive perfectionism: Developmental origins and association with depression proneness. Personality and Individual Differences, 33, 921-935.

Gnilka, P. B., Ashby, J. S. ve Noble, C. M. (2011). Adaptive and maladaptive perfectionism as mediators of adult attachment styles and depression, hopelessness, and life satisfaction. Journal of Counseling \& Development, 91, 78-86.

Frost, R. O., Marten, P. A., Lahart, C. ve Rosenblate, R. (1990). The dimensions of perfectionism. Cognitive Therapy and Research, $14,449-468$.

Hawkley, L. C., Burleson, M. H., Berntson, G. G. ve Cacioppo, J. T. (2003). Loneliness in everyday life: Cardiovascular activity, ppsychosocial context, and health behaviors. Journal of Personality and Social Psychology, 85, 105-120.

Hawkley, L. C. ve Cacioppo, J. T. (2010). Loneliness matters: A theoretical and empirical review of consequences and mechanisms. Annals of Behavioral Medicine, 40, 218-227.

Hewitt, P. L. ve Flett, G. L. (1991). Perfectionism in the self and social contexts: Conceptualization, assessment, and association with psychopathology, Journal of Personality and Social Psychology, 60, 465-470.

Jackson, T., Soderlind, A. ve Weiss, K. E. (2000). Personality traits and quality of relationships as predictors of future loneliness among American college students. Social Behaviour And Personality, 28(5), 463-470.

Karababa, A. ve Dilmaç, B. (2016). Ergenlerde yalnızlığın yordayıcıları olarak TA ve değerler. Eğitim ve Bilim, 41(187), 63-77.

Karataş-Karayel, G. (2011). Ergenlerde yalnızlığın yordayıcısı olarak mükemmelliyetçilik. Yüksek Lisans Tezi, Muğla Üniversitesi, Muğla.

Kaya, F. ve Birol, Z. N. (2018). Üniversite öğrencilerinin yalnızlık ve mükemmelliyetçilik düzeyleri arasındaki ilişkide duygusal zekanın aracılık rolü. Kastamonu Üniversitesi Eğitim Fakültesi Dergisi, 26(6), 1793-1802.

Keldal, G. ve Atli, A. (2016). University students' personality traits as predictors of their loneliness levels, Çukurova Üniversitesi Eğitim Fakültesi Dergisi, 45(2), 131-146.

Kırdök, O. (2004). Olumlu ve olumsuz mükemmeliyetçilik ölçeği geliştirme çalışması. Yüksek Lisans Tezi, Çukurova Üniversitesi, Adana.

Kong, F. ve You, X. (2013). Loneliness and self-esteem as mediators between social support and life satisfaction in late adolescence. Social Indicators Research, 110(1), 271-279.

McWhirter, B. T. (1990). Loneliness: A review of current literature with implications for counseling and research. Journal of Counseling and Development, 68, 417-422.

Erol-Öngen, D. (2009). The relationship between perfectionism and aggression among adolescents. Procedia Social and Behavioral Sciences, 1, 1073-1077.

Page, R. M., Yanagishita, J., Suwanteerangkul, J., Zarco, E. P., Mei-Lee, C. ve Miao, N. F. (2006). Hopelessness and loneliness among suicide attempters in school-based samples of Taiwanese, Philippine and Thai adolescents. School Psychology International, 27(5), 583-598.

Park, Y. ve Chang, E. C. (2004). Perfectionism and loneliness as predictors of depressive symptoms: A test of an integrative model. Journal of Young Investigators, 10(1).

Peplau, L. A. (1985). Loneliness research: Basic concepts and findings. In I. G. Sarason \& B. R Sarason (Eds.). Social support: theory, research and applications (pp. 269-286). Boston: Martinus Nijhoff Publishers.

Peplau, L. A. (1988). Loneliness: New directions in research. Proceedings of the 3rd National Conference on Psychiatric Nursing. Montreal: Quebec.

Peplau, L. A. ve Perlman, D. (1982). Perspectives on loneliness. In L. A. Peplau \& D. Perlman (Eds.). Loneliness: A sourcebook of current theory, research and therapy (pp. 1-18). New York: Wiley.

Perlman, D. ve Peplau, L. A. (1981). Toward a social psychology of loneliness. In S. Duck \& R. Gilmour (Eds.). Personal relationship in disor$\operatorname{der}$ (pp. 31-55). London: Academic Press.

| Kastamonu Eğitim Dergisi, 27(3), 2019| 
Perlman, D. ve Peplau, L. A. (1984). Loneliness research: A survey of empirical findings. In L. A. Peplau \& S. Goldston (Eds.). Preventing the harmful consequences of severe and persistent loneliness (pp. 13-46). U.S.: Goverment Printing Office.

Perlman, D. ve Peplau, L. A. (1998). Loneliness. Encyclopedia of Mental Health, 2, 571-581.

Rubenstein, C. ve Shaver, P. (1982). The experience of loneliness. In L. A. Peplau \& D. Perlman (Eds.). Loneliness: A sourcebook of current theory, research and therapy (pp. 206-223). New York: Wiley.

Russell, D., Peplau, L. A. ve Cutrona, C. E. (1980). The revised UCLA Loneliness Scale: Concurrent and discriminant validity evidence. Journal of Personality and Social Psychology, 39(3), 472-480.

Russell, D., Peplau, L. A. ve Ferguson, M. L. (1978). Developing a measure of loneliness. Journal of Personality Assessment, 42(3), $290-294$.

Santrock, J. W. (2012). Ergenlik (14. baskı). (çev. edit. Didem Müge Siyez). Ankara: Nobel Yayınclık.

Santrock, J. W. (2014). Yaşam boyu gelişim (13. baskı). (çev. edit. Galip Yüksel). Ankara: Nobel Yayıncılık.

Slaney, R. B., Rice, G. K., Mobley, M., Trippi, J. ve Ashby, J. (2001). The revised Almost Perfect Scale. Measurement and evaluation in counseling and development, 34, 130-144.

Storch, E. A. ve Masia-Warner, C. (2004). The relationship of peer victimization to social anxiety and loneliness in adolescent females. Journal of Adolescence, 27, 351-362.

Teppers, E., Klimstra, T. A., Van-Damme, C., Luyckx, K., Vanhalst, J. ve Goossens, L. (2013). Personality traits, loneliness, and attitudes toward aloneness in adolescence. Journal of Social and Personal Relationships, 30(8), 1045-1063.

Vanhalst, J., Klimstra, T. A., Luyckx, K., Scholte, R. H. J., Engels, R. C. M. E. ve Goossens, L. (2012). The Interplay of loneliness and depressive symptoms across adolescence: Exploring the role of personality traits. Journal of Youth Adolescence, 41, 776-787.

Vanhalst, J., Luyckx, K., Scholte, R. H. J., Engels, R. C. M. E. ve Goossens, L. (2013). Low self-esteem as a risk factor for loneliness in adolescence: Perceived-but not actual-social acceptance as an underlying mechanism. Journal of Abnormal Child Psychology, 41(7), $1067-1081$.

Wang, K. T., Yuen, M. ve Slaney, R. B. (2009). Percetionism, depression, and life satisfaction a study of high school students in Hong Kong. Counseling Psychologist, 37(2), 249-274.

Weiss, R. S. (1973). Loneliness: The experience of emotion and social Isolation. Cambridge, Mass.: MIT Press.

Yarcheski, A., Mahon, N. E. ve Yarcheski, T. J. (2011). Stress, hope, and loneliness in young adolescents. Psychological Reports, 108(3), 919-922 